\title{
16s rRNA gene sequencing and radioisotopic analysis reveal the composition of
} ammonia acclimatized methanogenic consortia

Tian, Hailin; Treu, Laura; Konstantopoulos, Konstantinos; Fotidis, Ioannis ; Angelidaki, Irini

Published in:

Bioresource Technology

Link to article, DOI:

10.1016/j.biortech.2018.09.128

Publication date:

2019

Document Version

Peer reviewed version

Link back to DTU Orbit

Citation (APA):

Tian, H., Treu, L., Konstantopoulos, K., Fotidis, I., \& Angelidaki, I. (2019). 16s rRNA gene sequencing and radioisotopic analysis reveal the composition of ammonia acclimatized methanogenic consortia. Bioresource Technology, 272, 54-62. https://doi.org/10.1016/j.biortech.2018.09.128

\section{General rights}

Copyright and moral rights for the publications made accessible in the public portal are retained by the authors and/or other copyright owners and it is a condition of accessing publications that users recognise and abide by the legal requirements associated with these rights.

- Users may download and print one copy of any publication from the public portal for the purpose of private study or research.

- You may not further distribute the material or use it for any profit-making activity or commercial gain

- You may freely distribute the URL identifying the publication in the public portal 


\section{Accepted Manuscript}

16s rRNA gene sequencing and radioisotopic analysis reveal the composition of ammonia acclimatized methanogenic consortia

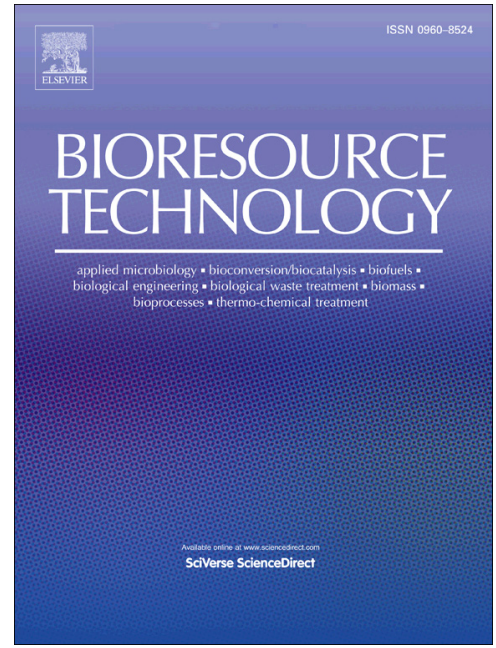

Hailin Tian, Laura Treu, Konstantinos Konstantopoulos, Ioannis A. Fotidis, Irini Angelidaki

PII: S0960-8524(18)31381-6

DOI: https://doi.org/10.1016/j.biortech.2018.09.128

Reference: BITE 20544

To appear in:

Bioresource Technology

Received Date:

2 August 2018

Revised Date:

24 September 2018

Accepted Date:

25 September 2018

Please cite this article as: Tian, H., Treu, L., Konstantopoulos, K., Fotidis, I.A., Angelidaki, I., 16s rRNA gene sequencing and radioisotopic analysis reveal the composition of ammonia acclimatized methanogenic consortia, Bioresource Technology (2018), doi: https://doi.org/10.1016/j.biortech.2018.09.128

This is a PDF file of an unedited manuscript that has been accepted for publication. As a service to our customers we are providing this early version of the manuscript. The manuscript will undergo copyediting, typesetting, and review of the resulting proof before it is published in its final form. Please note that during the production process errors may be discovered which could affect the content, and all legal disclaimers that apply to the journal pertain. 
16s rRNA gene sequencing and radioisotopic analysis reveal the composition of ammonia acclimatized methanogenic consortia

Hailin Tian, Laura Treu, Konstantinos Konstantopoulos, Ioannis A. Fotidis*, Irini Angelidaki

Department of Environmental Engineering, Technical University of Denmark, Bygningstorvet Bygning 115, DK-2800 Kgs. Lyngby, DK

*Corresponding Author: Ioannis A. Fotidis, Department of Environmental Engineering, Technical University of Denmark, Bygningstorvet Bygning 115, DK-2800 Kgs. Lyngby, Denmark, Phone: (+45) 45251418; Fax: (+45) 45933850; e-mail: ioanf@env.dtu.dk 


\section{Abstract}

Different mesophilic and thermophilic methanogenic consortia were acclimatised and enriched to extreme total ammonia (9.0 and $5.0 \mathrm{~g} \mathrm{NH}_{4}^{+}-\mathrm{N} \mathrm{L}^{-1}$, respectively) and free ammonia (1.0 and $1.4 \mathrm{~g} \mathrm{NH}_{3}-\mathrm{N} \mathrm{L}^{-1}$, respectively) levels in this study. $\left[2-{ }^{14} \mathrm{C}\right]$ acetate radioisotopic analyses showed the dominance of aceticlastic methanogenesis in all enriched consortia. According to $16 \mathrm{~S}$ rRNA gene sequencing result, in mesophilic consortia, methylotrophic Methanomassiliicoccus luminyensis was predominant, followed by aceticlastic Methanosarcina soligelidi. A possible scenario explaining the dominance of M. luminyensis includes the use of methylamine produced by Tissierella spp. and biomass build-up by metabolizing acetate. Nevertheless, further studies are needed to pinpoint the exact metabolic pathway of $M$. luminyensis. In thermophilic consortia, aceticlastic Methanosarcina thermophila was the sole dominant methanogen. Overall, results derived from this study demonstrated the efficient biomethanation ability of these ammonia-tolerant methanogenic consortia, indicating a potential application of these consortia to solve ammonia toxicity problems in future full-scale reactors.

\section{Keywords}

Anaerobic digestion; Enriched culture; Methanogenic pathway; Ammonia-tolerant microbial community; Methanomassiliicoccus luminyensis. 


\section{Introduction}

Anaerobic digestion (AD) is a widely used biotechnological process to treat a variety of biowaste and recover renewable energy $\left(\mathrm{CH}_{4}\right)$. It is a complex biological process that is mediated by different microbes (bacteria and archaea) and consists of four steps, named hydrolysis, acidogenesis, acetogenesis and methanogenesis. Acetate is the most important precursor of methane, with two main pathways involved in its catabolism: aceticlastic methanogenesis (Eq. (1)) and syntrophic acetate oxidation (SAO) coupled with hydrogenotrophic methanogenesis (Eq.(2-3)) (Zinder and Koch, 1984). The former pathway is mainly performed by Methanosaetaceae and Methanosarcinaceae, while the latter one by Methanococcales, Methanobacteriales, Methanocellales and Methanomicrobiales (Lyu and Lu, 2015).

$$
\begin{array}{lll}
\mathrm{CH}_{3} \mathrm{COO}^{-}+\mathrm{H}_{2} \mathrm{O} \rightarrow \mathrm{CH}_{4}+\mathrm{HCO}_{3}^{-} & \Delta \mathrm{G}^{0^{\prime}}=-31.0 \mathrm{~kJ} \mathrm{~mol}^{-1} & \text { Eq. (1) } \\
\mathrm{CH}_{3} \mathrm{COO}^{-}+4 \mathrm{H}_{2} \mathrm{O} \rightarrow 2 \mathrm{HCO}_{3}^{-}+4 \mathrm{H}_{2}+\mathrm{H}^{+} & \Delta \mathrm{G}^{0^{\prime}}=+104.6 \mathrm{~kJ} \mathrm{~mol}^{-1} & \text { Eq. (2) } \\
\mathrm{HCO}_{3}^{-}+4 \mathrm{H}_{2}+\mathrm{H}^{+} \rightarrow \mathrm{CH}_{4}+3 \mathrm{H}_{2} \mathrm{O} & \Delta \mathrm{G}^{0^{\prime}}=-135.6 \mathrm{~kJ} \mathrm{~mol}^{-1} & \text { Eq. (3) }
\end{array}
$$

In recent years, several nitrogen-rich biowastes (e.g. poultry manure, pig manure, slaughterhouse waste, etc.) have been considered as feedstock for biogas production due to their high methane potential. However, ammonia, which is a major toxicant of the $\mathrm{AD}$ process, is also produced during anaerobic degradation of nitrogen-rich biowaste (Fotidis et al., 2017). Methanogenesis is generally considered to be the most vulnerable AD process step to ammonia toxicity (Yenigün and Demirel, 2013). Chen et al. (2008) reviewed that total ammonia $\left(\mathrm{TAN}=\mathrm{NH}_{4}{ }^{+}+\mathrm{NH}_{3}\right)$ concentrations ranging from 1.7 to 
$14.0 \mathrm{~g} \mathrm{NH}_{4}{ }^{+}-\mathrm{N} \mathrm{L}^{-1}$ could cause $50 \%$ loss of the methane potential, depending on the operational conditions. Additionally, free ammonia (FAN, $\mathrm{NH}_{3}$ ) levels, which depend on temperature, $\mathrm{pH}$ and TAN levels, were reported to be the most toxic form of ammonia due to intracellular interference on biological activities of the methanogens (Massé et al., 2014).

Recently, the use of ammonia-tolerant methanogenic consortia was proposed as a potential solution to alleviate the ammonia toxicity problem in anaerobic reactors (Hao et al., 2015). Enrichment of ammonia-tolerant consortia, at both mesophilic and thermophilic conditions, is of great interest to optimize the utilization of nitrogen-rich substrates. Some researchers have already acclimatized different methanogenic cultures to high ammonia levels under mesophilic and thermophilic conditions (Tian et al., 2017). However, the microbiological characteristics of such consortia are still not clear. For example, it was reported (Sun et al., 2014; Müller et al., 2016) that hydrogenotrophic methanogens became dominant at high ammonia levels (>3.0 $\mathrm{g} \mathrm{NH}_{4}{ }^{+}$ $\mathrm{N} \mathrm{L}^{-1}$ ) with a simultaneous increase of the relative abundance of the syntrophic acetate oxidising bacteria (SAOB). Moreover, Methanomicrobiales and/or Methanobacteriales were detected to be predominant at TAN levels higher than 2.8 and up to $19 \mathrm{~g} \mathrm{NH}_{4}{ }^{+}-\mathrm{N}$ $\mathrm{L}^{-1}$ (Poirier et al., 2017; Ruiz-Sánchez et al., 2018). However, many researchers have presented controversial observations. For example, a member of aceticlastic Methanosarcinaceae was found to be the dominant methanogen in a mesophilic culture that was stepwise acclimatized in batch reactors above $5.0 \mathrm{~g} \mathrm{NH}_{4}^{+}-\mathrm{N} \mathrm{L}^{-1}$ (Fotidis et al., 2013). Furthermore, Tian et al. (2018b) found that Methanosarcina spp. were the most abundant archaea in continuous reactors at FAN levels above $750 \mathrm{mg} \mathrm{NH}_{3}-\mathrm{N} \mathrm{L}^{-1}$. Considering these contradictions, further investigation on the ammonia-tolerant 
methanogenic consortia is necessary. Moreover, besides methanogens, SAOB were also reported to play an important role on catabolizing acetate under high ammonia stress. Up to date, only three mesophilic SAOB (i.e. Clostridium ultunense (Schnürer, 1996), Syntrophaceticus schinkii (Westerholm et al., 2010) and Tepidanaerobacter acetatoxydans (Westerholm et al., 2011)) and two thermophilic SAOB (i.e. Thermacetogenium phaeum (Hattori et al., 2000) and Pseudothermotoga lettingae (Balk et al., 2002)) have been isolated. Some microbes without isolation, belonging to genus Coprothermobacter, orders Bacteroidales, Clostridiales and Thermoanaerobacterales, and phylum Thermotogae were also proposed to perform SAO (Nobu et al., 2015; Müller et al., 2016). Thus, a comprehensive and deep insight into the whole biomethanation community (archaea and bacteria) of ammonia-tolerant consortia is of great relevance to facilitate the way of developing and utilizing the microbiota to overcome ammonia inhibition. This knowledge will allow applying efficiently new biological methods (e.g. bioaugmentation technology), based on ammonia-tolerant consortia, to overcome the ammonia toxicity effect (Fotidis et al., 2014b).

Although the microbial community composition gives a good insight on the ammonia-tolerant consortia, the dominant methanogenic pathway should also be identified. This will allow to assess the importance of different methanogens and especially those that can perform both aceticlastic and hydrogenotrophic pathway, such as Methanosarcina species (De Vrieze et al., 2012). Radioisotopic analyses with labelled methyl group $\left[2-{ }^{14} \mathrm{C}\right]$ of sodium acetate can be used to identify the dominant acetate methanogenic pathway (Schnürer and Nordberg, 2008; Fotidis et al., 2013). Thus, it is a great opportunity to combine the radioisotopic analysis with the advanced 
microbial sequencing technology to understand fully the microbial characteristics of the ammonia-tolerant methanogenic consortia.

Therefore, the main aims were first, to enrich different methanogenic cultures adapted to high ammonia levels at both mesophilic and thermophilic conditions; second, to apply a combination of $16 \mathrm{~S}$ rRNA gene sequencing and radioisotopic acetate pathway analysis to characterize the ammonia-tolerant methanogenic consortia. To fulfil these aims, two mesophilic and three thermophilic inocula from different full-scale biogas plants, were enriched with stepwise increased ammonia levels in batch reactors. Furthermore, the final ammonia-tolerant consortia were characterized by deciphering the microbial composition and identifying the dominant acetate methanogenic pathway.

\section{Material and methods}

\subsection{Initial inocula}

Two mesophilic (Fangel (M1) and Hashøj (M2)) and three thermophilic (Blåhøj (T1), Ribe (T2) and Snertinge (T3)) initial inocula were used in this study. All inocula were derived from Danish full-scale biogas plants. All the reactors were manure-based continuously stirred tank reactors (CSTR) with cattle and pig manure as main feedstocks, while different biomasses were used as secondary feedstocks (e.g. poultry manure, mink slurry, food industry waste, medicinal biowaste etc.). The detailed characteristics of the used inocula and the operational parameters of the five full-scale biogas plants are shown in Table 1.

\subsection{Enrichment procedure}


Batch reactors with 40 and $118 \mathrm{~mL}$ working and total volume, respectively, were used to enrich the ammonia-tolerant consortia. Basal anaerobic medium (BA medium (E-supplementary data)), containing the basic nutrients and microelements for microbial growth (Angelidaki et al., 1990), was used as cultivation medium throughout the experiment. The inoculum/working volume ratio was set as $12.5 \%(\mathrm{v} / \mathrm{v})$. The whole enrichment processes were divided into seven steps (the details experimental setup is depicted in Table 2). During steps 1 to 5 , mixed $\mathrm{N}_{2} / \mathrm{CO}_{2}(80 / 20 \% \mathrm{v} / \mathrm{v})$ gas was used to flush the reactors' content, to create anoxic conditions and keep the $\mathrm{pH}$ at $7.0 \pm 0.1$. Meanwhile, all enrichment batches were started from TAN levels of $3.0 \mathrm{~g} \mathrm{NH}_{4}^{+}-\mathrm{N} \mathrm{L}^{-1}$, and then stepwise $\left(1.0 \mathrm{~g} \mathrm{NH}_{4}{ }^{+}-\mathrm{N} \mathrm{L}^{-1}\right.$ each step) increased to $7.0 \mathrm{~g} \mathrm{NH}_{4}{ }^{+}-\mathrm{N} \mathrm{L}^{-1}$. At step 6 and 7, the $\mathrm{pH}$ of the reactors was increased to $8.0 \pm 0.1$ by flushing with pure $\mathrm{N}_{2}$ gas and adding $\mathrm{NaOH}$ solution (when necessary) to create a high FAN environment. Moreover, for mesophilic inocula, TAN levels increased from $7.0 \mathrm{~g} \mathrm{NH}_{4}{ }^{+}-\mathrm{N} \mathrm{L}^{-1}$ (Step 6) to $9.0 \mathrm{~g}$ $\mathrm{NH}_{4}{ }^{+}-\mathrm{N} \mathrm{L}^{-1}$ (Step 7). At the same time, for the thermophilic inocula, the TAN levels were decreased from 7.0 to $5.0 \mathrm{~g} \mathrm{NH}_{4}{ }^{+}-\mathrm{N} \mathrm{L}^{-1}$ (Step 6), due to the already high FAN levels $\left(1.4 \mathrm{~g} \mathrm{NH}_{3}-\mathrm{N} \mathrm{L}^{-1}\right)$ at $5.0 \mathrm{~g} \mathrm{NH}_{4}^{+}-\mathrm{N} \mathrm{L}^{-1}$.

Throughout the enrichment process, $\mathrm{Na}_{2} \mathrm{~S} \cdot 9 \mathrm{H}_{2} \mathrm{O}$ (final concentration: $62.5 \mathrm{mg} \mathrm{L}^{-1}$ ) and yeast extract (final concentration: $0.2 \mathrm{~g} \mathrm{~L}^{-1}$ ) were added to all the bottles to ensure anaerobic conditions and supplement of necessary vitamins, amino acids and other growth factors, respectively. Furthermore, acetate $\left(2 \mathrm{~g} \mathrm{~L}^{-1}\right.$ during all the enrichment steps except for the last step, which $3 \mathrm{~g} \mathrm{~L}^{-1}$ were used to get a high biomass concentration for microbial analyses) was used as carbon source, while ammonium chloride was chosen as ammonia source. After closing with butyl rubber stoppers and sealing with aluminium caps, all the bottles were incubated in triplicates at their 
corresponding temperatures. The acclimatization at each step was stopped when the stationary phase was achieved and the methane production was at least $90 \%$ of the maximum theoretical expected production.

\subsection{Radioisotopic experimental setup}

A radioisotopic test using labelled $\left[2-{ }^{14} \mathrm{C}\right]$ sodium acetate (Amersham Pharmacia Biotech, UK) was performed on the final enriched consortia, to identify the dominant acetate methanogenic pathway. To follow the methanogenic pathway, each enriched consortium was mixed with BA medium and introduced to batch reactors with three different setups: 1) blanks, to evaluate the background methane production; 2) control, with unlabelled acetate $\left(1.0 \mathrm{~g} \mathrm{~L}^{-1}\right)$, to follow methane production; 3) labelled bottles, with both labelled $\left(54.90 \pm 0.46 \mathrm{KBq} \mathrm{L}^{-1}\right)$ and unlabelled $\left(1.0 \mathrm{~g} \mathrm{~L}^{-1}\right)$ acetate, to evaluate the ${ }^{14} \mathrm{CO}_{2} /{ }^{14} \mathrm{CH}_{4}$ ratio. The ${ }^{14} \mathrm{C}$ radioisotopic activity was measured by a liquid scintillation counter (Hidex 300 SL; LabLogic Company, United Kingdom), and the samples were prepared according to Fotidis et al. (2013). To release the dissolved ${ }^{14} \mathrm{CO}_{2}$ in the reactors with $\left[2-{ }^{14} \mathrm{C}\right]$ acetate addition, $2 \mathrm{~mL} 7.2 \mathrm{M} \mathrm{HCl}$ solution was added into each reactor to acidify the solution when methane production ceased. The produced ${ }^{14} \mathrm{CO}_{2}$ was trapped with $\mathrm{CO}_{2}$ absorber (Carbosorb ${ }^{\mathrm{R}}$-E; PerkinElmer Company). The produced ${ }^{14} \mathrm{CH}_{4}$ was oxidized to ${ }^{14} \mathrm{CO}_{2}$ in a tube furnace (at $850^{\circ} \mathrm{C}$ ) with copper oxide ( $\mathrm{CuO}$, Sigma-Aldrich) as catalyst, and trapped with a different aliquot of the same $\mathrm{CO}_{2}$ absorber. Meanwhile, the liquid sample from the reactors was mixed with distilled water to identify the residual $\left[2-{ }^{14} \mathrm{C}\right]$ acetate radioactivity. Finally, all the samples were mixed with scintillation liquid (Permafluor $\mathrm{E}^{+}$for ${ }^{14} \mathrm{CO}_{2}$ trapped samples and Optiphase Hisafe 3 for reactor liquid samples; PerkinElmer Company) before measuring with the scintillation counter. 


\subsection{Microbial analyses with amplicon sequencing}

To elucidate the microbial community composition, $90 \mathrm{~mL}$ samples of the enriched consortia were taken from the last step of the enrichment process (i.e. step 7 for mesophilic and step 6 for thermophilic enriched cultures). PowerSoil@ DNA Isolation Kit (MO BIO laboratories Inc., Carlsbad, CA USA) was used for the genomic DNA extraction. Furthermore, an extra cleaning step with Phenol: Chloroform: Isoamyl Alcohol (25: 24: 1) (Sigma-Aldrich) was performed to guarantee the DNA quality. The quantity and quality of the extracted DNA were determined by NanoDrop 2000 (ThermoFisher Scientific, Waltham, MA). PCR amplification on V4 region of 16S rRNA gene was conducted using 515F/806R universal primers, and Illumina MiSeq platform (Ramaciotti Centre for Genomics, Kensington, Australia) was used to generate paired-end sequencing reads $(2 \times 250 \mathrm{bp})$. CLC Workbench software (V.8.0.2) with microbial genomics module plugin was used to analyse the raw sequence data for quality filtering, diversity analyses, OTUs (operational taxonomic units) clustering and taxonomy identification (Greengenes v13_5 database). The adequate sequencing depth for all samples was ensured by rarefaction curves (E-supplementary data). Principal Coordinate Analysis (PCoA) was used to estimate beta diversity. BLASTN search against NCBI (National Center for Biotechnology Information) 16S ribosomal RNA sequences (Bacteria and Archaea) database was performed on the interesting (relative abundance higher than $0.5 \%$, provided by CLC software) OTUs' consensus sequences to verify the taxonomic assignment (E-supplementary data). Furthermore, relative abundance of the interesting OTUs was presented as heat maps using Multi experiment viewer software (MeV 4.9.0) (Saeed et al., 2006). The raw sequencing reads were 
deposited in Sequence Read Archive (SRA) database (http://www.ncbi.nlm.nih.gov/sra) under the ID PRJNA475596.

\subsection{Physicochemical analyses}

TS, VS, and TAN were measured according to APHA (2012). The $\mathrm{pH}$ was measured by PHM99 LAB pH meter. The methane production was determined by a gas chromatograph (Trace 1310 GC-TCD, Thermo Fisher, Denmark) equipped with a thermal conductivity detector. A TracePLOT TG-BOND Q 26004-6030 column $(30 \mathrm{~m} \times 0.32 \mathrm{~mm}$ I.D., film thickness $10 \mu \mathrm{m})$ (Thermo Fisher) was used, and the column flow rate was $2.7 \mathrm{~mL} \mathrm{~min}^{-1}$. The temperature of the front inlet, oven and detector were $150^{\circ} \mathrm{C}, 70^{\circ} \mathrm{C}$ and $200^{\circ} \mathrm{C}$, respective. Helium was used as carrier gas. The VFA levels were measured through a gas-chromatograph (Shimadzu GC-2010, Kyoto, Japan) equipped with flame ionization detector and a FFAP fused silica capillary column (30 m $\times 0.53 \mathrm{~mm}$ i.d., film thickness $1.5 \mu \mathrm{m}$ ). The temperature of the injection port and the detector were $150^{\circ} \mathrm{C}$ and $230^{\circ} \mathrm{C}$, respectively. Nitrogen was used as carrier gas.

\subsection{Calculations and statistics}

OriginLab (OriginLab Corporation, Northampton, Massachusetts) program was used to perform all the statistical analyses and to prepare the figures.

\subsubsection{Free ammonia}

The FAN levels were calculated by the following equation:

$\mathrm{FAN}=\frac{\mathrm{TAN}}{1+\frac{10^{-\mathrm{pH}}}{K_{a}}}$ Eq. (4) 
Where $K_{a}$ is the dissociation constant determined by temperature and it equals to $1.29 \times 10^{-9}$ at mesophilic condition $\left(37 \pm 1^{\circ} \mathrm{C}\right)$ and $3.91 \times 10^{-9}$ at thermophilic condition $\left(55 \pm 1^{\circ} \mathrm{C}\right)$.

\subsubsection{Acetate methanogenic pathway}

The ratio of ${ }^{14} \mathrm{CO}_{2} /{ }^{14} \mathrm{CH}_{4}$ from the radioisotopic analyses was used to estimate the dominant acetate methanogenic pathway. It is generally accepted that the dominant acetate methanogenic pathway is aceticlastic when ${ }^{14} \mathrm{CO}_{2} /{ }^{14} \mathrm{CH}_{4}<1$, and SAO coupled with hydrogenotrophic methanogens is dominant when ${ }^{14} \mathrm{CO}_{2} /{ }^{14} \mathrm{CH}_{4}>1$ (Fotidis et al., 2013).

\subsubsection{Maximum specific growth rate}

The OriginLab software was used to calculate the maximum specific growth rate $\left(\mu_{\max }\right)$ of the methanogenic consortia according to the slope of the linear part of the semi-logarithmic graph of the methane production versus the incubation time (Gray et al., 2009).

\section{Results and discussion}

\subsection{Enriched cultures}

In four out of five enriched methanogenic consortia (except M1), the $\mu_{\max }$ decreased with the increase of ammonia levels during the enrichment process (Fig. 1), which agreed with previous observations of decreased growth rates at high ammonia levels (Yenigün and Demirel, 2013). The maximum $\mu_{\max }$ for each one of the cultures was observed during step 1 of the enrichment process (i.e. at the lowest ammonia levels), with the exception of culture M1 where the highest $\mu_{\max }$ was observed during steps 2 and 3 (no statistical difference, $p>0.05$ ). Ranging from 0.47 to $0.79 \mathrm{~d}^{-1}$, the maximum 
$\mu_{\max }$ of all the enriched cultures in this study was comparable with other studies. For example, Fotidis et al. (2013) observed $\mu_{\max }$ of acetate-fed methanogenic cultures varying from 0.3 to $0.7 \mathrm{~d}^{-1}$ at TAN levels between 2.0 and $5.0 \mathrm{~g} \mathrm{NH}_{4}^{+}-\mathrm{N} \mathrm{L}^{-1}$ for both mesophilic and thermophilic conditions. Moreover, the $\mu_{\max }$ of pure strains (Methanosarcina thermophila and Methanoculleus thermophilus) was also reported to be within 0.5 and $1.0 \mathrm{~d}^{-1}$ at FAN levels from 0.1 up to $1.4 \mathrm{~g} \mathrm{NH}_{3}-\mathrm{N} \mathrm{L}^{-1}$ (Tian et al., 2018a). However, the $\mu_{\max }$ of the enriched cultures, were significantly lower than the $\mu_{\max }$ measured in biomethanation microbiomes of several full-scale digesters (1.2 to 1.5 $\mathrm{d}^{-1}$ ) (Fotidis et al., 2014a). This could be explained by higher FAN levels $(0.39-0.86 \mathrm{~g}$ $\mathrm{NH}_{3}-\mathrm{N} \mathrm{L} \mathrm{L}^{-1}$ ) to which the enriched consortia were exposed, compared to the aforementioned study $\left(0.05-0.51 \mathrm{~g} \mathrm{NH}_{3}-\mathrm{N} \mathrm{L}^{-1}\right)$.

Even though the enrichment process ended with a certain degree of $\mu_{\max }$ reduction (Fig. 1), the results showed that the enriched ammonia-tolerant consortia were still able to work efficiently at high ammonia levels (i.e. TAN levels of 9.0 and $5.0 \mathrm{~g} \mathrm{NH}_{4}+-\mathrm{N} \mathrm{L}^{-1}$, and FAN levels of 1.0 and $1.4 \mathrm{~g} \mathrm{NH}_{3}-\mathrm{N} \mathrm{L}^{-1}$, under mesophilic and thermophilic conditions, respectively). The $\mu_{\max }$ of the final ammonia-tolerant consortia varied from 0.21 to $0.31 \mathrm{~d}^{-1}$ for all the samples, except for $\mathrm{T} 3$, which was significantly $(p<0.05)$ lower $\left(0.17 \mathrm{~d}^{-1}\right)$ than the others. However, efficient anaerobic degradation of poultry manure was possible with an overall $\mu_{\max }$ around $0.1 \mathrm{~d}^{-1}$ (Hunik et al., 1990), which indicates that the enriched cultures in the current study have adequate growth rates to mediate the digestion of ammonia-rich substrates in CSTR biogas reactors, considering that commonly used HRTs are in the range 13-25 days. Ammonia-tolerant microbial consortia with growth rates corresponding to doubling times of 2-3 days would stay in reactor and outcompete ammonia inhibited microbes at high ammonia loadings. 


\subsection{Methanogenic pathway}

The aceticlastic pathway $\left({ }^{14} \mathrm{CO}_{2} /{ }^{14} \mathrm{CH}_{4}<1\right)$ was identified to be the dominant acetate methanogenic pathway in all the ammonia-tolerant consortia (Fig. 2). This coincides with previous researches, where aceticlastic methanogenesis became dominant when TAN levels increased from 0.26 to $7.0 \mathrm{~g} \mathrm{NH}_{4}{ }^{+}-\mathrm{N} \mathrm{L}^{-1}$ (Fotidis et al., 2013). Moreover, based on stable carbon $\left(1,2-{ }^{13} \mathrm{C}\right)$ isotopic analysis, acetate was identified to be catabolised to methane through the aceticlastic pathway, regardless of ammonia concentration (Hao et al., 2015). On contrary, other researchers have found that the methanogenic pathway changed from aceticlastic to hydrogenotrophic when ammonia levels increased (Schnürer and Nordberg, 2008). This difference of the dominant acetate methanogenic pathway at high ammonia levels might be due to the different operational conditions (e.g. various substrates, different HRTs, etc.) of the biogas plant, where the initial inocula derived from.

\subsection{Global microbial diversity}

In total, more than six million raw sequences were generated from the triplicate samples of the five ammonia-tolerant consortia. Beta diversity was expressed based on PCoA (Fig. 3), with PCo1 and PCo2 explaining $81 \%$ and $8 \%$ variation in diversity, respectively. Additionally, the PCoA showed a big difference between mesophilic and thermophilic consortia, which was expected because temperature is a crucial factor influencing the microbial composition (Treu et al., 2018). However, among the three thermophilic ammonia-tolerant consortia, T1 and T2 shared similarity, but they were different from T3. This difference might be contribute to the lower $\mu_{\max }$ that $\mathrm{T} 3 \mathrm{had}$ at the last acclimation step compared to T1 and T2 (Fig. 1), which indicated that the final microbiome compositions could be shaped differently by the ammonia toxicity. 


\subsection{Microbial community composition}

In mesophilic consortia, relative abundance of archaea reached approximately $30 \%$ and the other $70 \%$ was bacteria, while in thermophilic consortia, archaea varied between $19 \%$ and $24 \%$ (E-supplementary data). The abundance of archaea (methanogens) in these consortia was significantly higher compared to many previous studies investigating the microbial composition in AD reactors (Fitamo et al., 2017; Zhu et al., 2017), indicating that the enrichment process with single and simple substrate aiming to obtain high abundance of ammonia-tolerant methanogens was successful.

\subsubsection{Mesophilic enriched consortia}

At mesophilic conditions, only three orders were found among methanogens: E2, Methanosarcinales and Methanomicrobiales (Fig. 4a). In these three orders, only three genera were found (Fig. 4b): Methanomassiliicoccus spp. (relative abundance of $51 \%$ in M1 and $65 \%$ in M2 within archaea community), Methanosarcina spp. (47\% in M1 and $34 \%$ in M2) and Methanoculleus sp. (2\% in M1 and 1\% in M2). By conducting a BLASTN search, the two OTUs (Fig. 5a) identified as Methanomassiliicoccus spp. were assigned to Methanomassiliicoccus luminyensis with $96-98 \%$ similarity. $M$. luminyensis was a newly reported methanogen, isolated from human faeces and recently found in biogas reactors (Popp et al., 2016; Lin et al., 2017). Furthermore, $M$. luminyensis was found to be abundant at TAN levels around 6.0-7.0 $\mathrm{g} \mathrm{NH}_{4}{ }^{+}-\mathrm{N} \mathrm{L}^{-1}$ in lab and full scale reactors fed with protein-rich substrates (Ács et al., 2013; Ruiz-Sánchez et al., 2018), which indicates its high tolerance to ammonia toxicity. The predominance of M. luminyensis was a surprise, since the dominant acetate methanogenic pathways of M1 and M2 were found to be aceticlastic (Fig. 2). M. luminyensis cannot use acetate to produce methane but only methanol, tri-, di- and monomethylamine (strict 
methylotrophic) with the presence of hydrogen as the electron donor (Dridi et al., 2012). A possible explanation could be that all or some of these specific substrates (i.e. methanol, tri-, di- and monomethylamine), were produced from the degradation of amino acids (derived from yeast extract included in the medium) and/or the cells lysis of species that could not adapt to high ammonia levels (Harms et al., 1998; Dorokhov et al., 2015). This was also supported by the fact that several bacterial OTUs were assigned to genus Tissierella and this genus can produce methylamine from different amino acids (Farrow et al., 1995; Harms et al., 1998). Moreover, without having the ability to use acetate to produce methane, Methanomassiliicoccus spp. have the genes to use acetate to produce energy for building biomass (KEGG-Database, 2018), which could be an additional explanation for the high abundance of $M$. luminyensis. Last but not least, it was reported that acetate can be reduced to methanol by some bacteria, such as Shewanella putrefaciens (Vajda et al., 2011). Even though this specific bacterium was not detected, there might be some uncultured OTUs that can perform this metabolic pathway. Unfortunately, 16s rRNA sequencing analysis only provides information about taxonomic assignment, but not about genomic characteristics and the functional annotation. Moreover, the sequencing length (251bp) of 16s rRNA amplicon sequencing technology also limited the detailed analysis on species level. Therefore, on the one hand, further investigations based on advanced techniques like total random sequences could be performed to further elucidate the metabolic pathway of Methanomassiliicoccus spp. detected in this study. On the other hand, isolation of the Methanomassiliicoccus spp. could also be done with methylated one-carbon compounds, and then assesses their metabolic pathway. However, the detailed metabolic study of 
one specific species is beyond the scope of the current study, thus not being performed and analysed in this paper.

The second most abundant methanogen was found to be Methanosarcina soligelidi with a similarity of $98 \%$. The abundance of $M$. soligelidi at high ammonia levels was in accordance to previous study reporting that Methanosarcina sp. was dominant in continuous reactors at TAN levels up to $10.0 \mathrm{~g} \mathrm{NH}_{4}{ }^{+}-\mathrm{N} \mathrm{L}^{-1}$ (Tian et al., 2018b). The methanogenic pathway in the aforementioned research was not identified thus a possible hydrogenotrophic pathway was proposed. However, the radioisotopic analysis in the present study indicated that Methanosarcina spp. still performed aceticlastic pathway at such high ammonia levels.

Bacterial phyla Bacteroidetes, Firmicutes and Synergistetes constituted more than $90 \%$ of the total community (Fig. 4c). However, for almost half of the bacterial OTUs, they were not possible to reach taxonomic assignation at genus level (Fig. 4d). The most abundant OTU (relative abundance of $38 \%$ in $\mathrm{M} 1$ and $25 \%$ in $\mathrm{M} 2$ with respect to bacterial community) was represented by Tepidimicrobium sp. (Fig. 5a), which can be assigned to Tepidimicrobium xylanilyticum. T. xylanilyticum is an anaerobic xylanolytic bacterium that uses a variety of carbohydrates and proteinaceous compounds (Niu et al., 2009), thus its high abundance could be attributed to the degradation of yeast extract and dead cells under high ammonia conditions. Similarly, two other abundant OTUs, also able to catabolize amino acids, were identified to be $100 \%$ similar to Fermentimonas caenicola and Aminobacterium colombiense, respectively. Specifically, it has been reported that $F$. caenicola grows on yeast extract, producing mainly acetate, $\mathrm{CO}_{2}$ and $\mathrm{H}_{2}$ (Hahnke et al., 2016); additionally, A. colombiense is an amino acid 
degrading bacterium (Baena et al., 1998), and yeast extract is mainly composed by different types of amino acids .

Four very interesting OTUs, with total relative abundances of $6 \%$ and $15 \%$ in $\mathrm{M} 1$ and M2 with respect to bacteria community, respectively, were assigned to genus Tissierella, which was reported to produce methylamine from different amino acids (Farrow et al., 1995; Harms et al., 1998). Thus, it seems that the presence of Tissierella spp. was the main reason for the high abundance of the strict methylotrophic $M$. luminyensis discussed above. However, it is not possible to claim that only methylamine (and not acetate) was the sole carbon source that $M$. luminyensis was metabolizing, because metabolomics analysis was not part of the present study.

Two more OTUs that had relative abundance around 1-2\%, were assigned with a $98 \%$ similarity to Clostridium ultunense, which is a well-known SAOB in mesophilic biogas reactors (Schnürer, 1996). This low abundance of SAOB was correlated with the low abundant hydrogenotrophic Methanoculleus sp. (Fig. 5a), indicating a certain degree of hydrogenotrophic methanogenesis even with aceticlastic pathway as the dominant acetate metabolic pathway. However, it is also possible that hydrogen derived from the SAOB was used by the $M$. luminyensis as electron donor to produce $\mathrm{CH}_{4}$ from methanol, tri-, di- and monomethylamine (Dridi et al., 2012).

\subsubsection{Thermophilic enriched consortia}

Methanosarcinales, Methanomicrobiales, Methanobacteriales and E2 orders composed of the methanogens of all thermophilic enriched cultures (Fig. 4a). The most abundant genus was Methanosarcina (Fig. 4b) and the most abundant OTU was identified to be $100 \%$ similar to Methanosarcina thermophila (Fig. 5b), a well-known aceticlastic methanogenic species (Zinder et al., 1985). The high relative abundance of 
M. thermophila, varying between $65 \%$ and $95 \%$ within the archaea community in all enriched cultures, was consistent with the dominant aceticlastic methanogenic pathway found in radioisotopic analysis (Fig. 2). The other two abundant OTUs were $100 \%$ similar to hydrogenotrophic Methanoculleus thermophilus (relative abundance of $10 \%$ in $\mathrm{T} 1$ and $\mathrm{T} 3$, and 1\% in T2) and Methanothermobacter thermautotrophicus (relative abundance varying between 2 to 26\%) (Fig. 5b), respectively. Previous researches have reported the ability of the aforementioned species to efficiently produce methane under high TAN $\left(>7.0 \mathrm{NH}_{4}{ }^{+}-\mathrm{N} \mathrm{L}^{-1}\right)$ and FAN $\left(>0.9 \mathrm{~g} \mathrm{NH}_{3}-\mathrm{N} \mathrm{L}^{-1}\right)$ level (Hao et al., 2015; Tian et al., 2018a). Furthermore, M. thermautotrophicus was also found with high abundance in reactors with ammonia-rich substrates, such as chicken manure (Niu et al., 2013).

The bacterial community of the thermophilic ammonia-tolerant consortia mainly consisted of three phyla: Firmicutes, Synergistetes and Thermotogae (Fig. 4c). Similar to the mesophilic consortia, $25 \%$ to $55 \%$ of the thermophilic bacteria were unable to be assigned at genus level (Fig. 4d). The most abundant OTU in all three consortia samples was Anaerobaculum mobile 5 (varying from $18 \%$ to $34 \%$ ), which was reported to be a fermentative bacterium degrading peptides (Menes and Muxí, 2002) and can utilize acetate as carbon source to grow. Given that yeast extract (used in the medium) contains peptides and acetate was the main carbon source in this study, it could explain the thriving of the A. mobile. Additionally, several OTUs belonging to Tepidmicrobium spp., and several high abundant OTUs, such as MBA08 sp. 10 (90\% similarity with Hydrogenispora ethanolica) and Clostridiaceae sp. $11(90 \%$ similarity with Caldicoprobacter spp.) were also suspected to be related to the degradation of compounds contained in yeast extract (Niu et al., 2009; Bouanane-Darenfed et al., 2013; Liu et al., 2014). 
Notably, the well-known SAOB S. schinkii was also detected with relative abundance varying between 1 to $6 \%$ in all the consortia. Moreover, the second most abundant OTU in T1, Clostridia sp. 6, had a 90\% similarity to Moorella humiferrea, which was reported to be phylogenetically close to SAOB T. phaeum (Hattori et al., 2000). Similarly, the candidate genus S1 (including two OTUs and one was the second most abundant OTU in T3), which belonged to family Thermotogaceae and phylum thermotogae, was also suggested to perform SAO (Nobu et al., 2015). Taking all the above OTUs into account, the highest relative abundance of SAOB was found in T3, followed by $\mathrm{T} 2$ and $\mathrm{T} 1$, which is directly correlated with the relative abundance distribution of the hydrogenotrophic methanogens among the three consortia $(\mathrm{T} 3>\mathrm{T} 1>\mathrm{T} 2)$.

\section{Conclusions}

This study revealed that aceticlastic methanogenesis was the dominant acetate methanogenic pathway at extremely high ammonia levels, mediated mainly by $M$. soligelidi and $M$. thermophila under mesophilic and thermophilic conditions, respectively. Surprisingly, strict methylotrophic $M$. luminyensis was the most abundant methanogen in mesophilic ammonia-tolerant consortia. This could be attributed to the unique $M$. luminyensis metabolism, which can use methylamine, produced from the amino acids, to form $\mathrm{CH}_{4}$ and, at the same time, acetate only to produce biomass. However, even with dominant aceticlastic methanogenesis, SAOB and hydrogenotrophic methanogens (Methanoculleus spp. and Methanothermobacter spp.) were still detected, especially under thermophilic conditions.

\section{Acknowledgements}


This work was supported by Energinet.dk under the project framework ForskEL "MicrobStopNH $\mathrm{N}_{3}$-Innovative bioaugmentation strategies to tackle ammonia inhibition in anaerobic digestion process" (program no. 2015-12327). Hailin Tian would like to thank for the financial support from China Scholarship Council. The authors thank Hector Garcia for his technical support during the experiments.

\section{Appendix A. E-supplementary data}

E-supplementary data of this article can be found in online version of the paper.

\section{References}

[1] Ács, N., Kovács, E., Wirth, R., Bagi, Z., Strang, O., Herbel, Z., Rákhely, G., Kovács, K.L., 2013. Changes in the Archaea microbial community when the biogas fermenters are fed with protein-rich substrates. Bioresour. Technol. 131, $121-127$.

[2] Angelidaki, I., Petersen, S.P., Ahring, B.K., 1990. Effects of lipids on thermophilic anaerobic digestion and reduction of lipid inhibition upon addition of bentonite. Appl. Microbiol. Biotechnol. 33, 469-472.

[3] APHA, 2012. Standard Methods for the Examination of Water and Wastewater. American Public Health Association, Washington, DC.

[4] Baena, S., Fardeau, M.L., Labat, M., Ollivier, B., Thomas, P., Garcia, J.L., Patel, B.K.C., 1998. Aminobacterium colombiensegen. nov. sp. nov., an Amino Aciddegrading Anaerobe Isolated from Anaerobic Sludge. Anaerobe 4, 241-250.

[5] Balk, M., Weijma, J., Stams, A.J.M., 2002. Thermotoga lettingae sp. nov., a novel thermophilic, methanol-degrading bacterium isolated from a thermophilic anaerobic reactor. Int. J. Syst. Evol. Microbiol. 52, 1361-1368. 
[6] Bouanane-Darenfed, A., Ben Hania, W., Hacene, H., Cayol, J.-L., Ollivier, B., Fardeau, M.-L., 2013. Caldicoprobacter guelmensis sp. nov., a thermophilic, anaerobic, xylanolytic bacterium isolated from a hot spring. Int. J. Syst. Evol. Microbiol. 63, 2049-2053.

[7] Chen, Y., Cheng, J.J., Creamer, K.S., 2008. Inhibition of anaerobic digestion process: a review. Bioresour. Technol. 99, 4044-64.

[8] De Vrieze, J., Hennebel, T., Boon, N., Verstraete, W., 2012. Methanosarcina: The rediscovered methanogen for heavy duty biomethanation. Bioresour. Technol. 112, $1-9$.

[9] Dorokhov, Y.L., Shindyapina, A.V., Sheshukova, E.V., Komarova, T.V., 2015. Metabolic methanol: molecular pathways and physiological roles. Physiol. Rev. $95,603-44$.

[10] Dridi, B., Fardeau, M.-L., Ollivier, B., Raoult, D., Drancourt, M., 2012. Methanomassiliicoccus luminyensis gen. nov., sp. nov., a methanogenic archaeon isolated from human faeces. Int. J. Syst. Evol. Microbiol. 62, 1902-1907.

[11] Farrow, J.A.E., Lawson, P.A., Hippe, H., Gauglitz, U., Collins, M.D., 1995. Phylogenetic Evidence that the Gram-Negative Nonsporulating Bacterium Tissierella (Bacteroides) praeacuta Is a Member of the Clostridium Subphylum of the Gram-Positive Bacteria and Description of Tissierella creatinini sp. nov. Int. J. Syst. Evol. Microbiol. 45, 436-440.

[12] Fitamo, T., Treu, L., Boldrin, A., Sartori, C., Angelidaki, I., Scheutz, C., 2017. Microbial population dynamics in urban organic waste anaerobic co-digestion with mixed sludge during a change in feedstock composition and different hydraulic retention times. Water Res. 118, 261-271. 
[13] Fotidis, I.A., Karakashev, D., Angelidaki, I., 2014a. The dominant acetate degradation pathway/methanogenic composition in full-scale anaerobic digesters operating under different ammonia levels. Int. J. Environ. Sci. Technol. 11, $2087-$ 2094.

[14] Fotidis, I.A., Karakashev, D., Kotsopoulos, T.A., Martzopoulos, G.G., Angelidaki, I., 2013. Effect of ammonium and acetate on methanogenic pathway and methanogenic community composition. FEMS Microbiol. Ecol. 83, 38-48.

[15] Fotidis, I.A., Treu, L., Angelidaki, I., 2017. Enriched ammonia-tolerant methanogenic cultures as bioaugmentation inocula in continuous biomethanation processes. J. Cleaner Prod. 166, 1305-1313.

[16] Fotidis, I.A., Wang, H., Fiedel, N.R., Luo, G., Karakashev, D.B., Angelidaki, I., 2014b. Bioaugmentation as a solution to increase methane production from an ammonia-rich substrate. Environ. Sci. Technol. 48, 7669-76.

[17] Gray, N.D., Sherry, A., Larter, S.R., Erdmann, M., Leyris, J., Liengen, T., Beeder, J., Head, I.M., 2009. Biogenic methane production in formation waters from a large gas field in the North Sea. Extremophiles 13, 511-9.

[18] Hahnke, S., Langer, T., Koeck, D.E., Klocke, M., 2016. Description of Proteiniphilum saccharofermentans sp. nov., Petrimonas mucosa sp. nov. and Fermentimonas caenicola gen. nov., sp. nov., isolated from mesophilic laboratoryscale biogas reactors, and emended description of the genus Proteiniphilum. Int. J. Syst. Evol. Microbiol. 66, 1466-1475.

[19] Hao, L., Lü, F., Mazéas, L., Desmond-Le Quéméner, E., Madigou, C., Guenne, A., Shao, L., Bouchez, T., He, P., 2015. Stable isotope probing of acetate fed anaerobic batch incubations shows a partial resistance of acetoclastic 
methanogenesis catalyzed by Methanosarcina to sudden increase of ammonia level. Water Res. 69, 90-99.

[20] Harms, C., Schleicher, A., Collins, M.D., Andreesen, J.R., 1998. Tissierella creatinophila sp. nov., a Gram-positive, anaerobic, non-spore-forming, creatininefermenting organism. Int. J. Syst. Evol. Microbiol. 48, 983-993.

[21] Hattori, S., Kamagata, Y., Hanada, S., Shoun, H., 2000. Thermacetogenium phaeum gen. nov., sp. nov., a strictly anaerobic, thermophilic, syntrophic acetateoxidizing bacterium. Int. J. Syst. Evol. Microbiol. 50 Pt 4, 1601-1609.

[22] Hunik, J.H., Hamelers, H.V.M., Koster, I.W., 1990. Growth-rate inhibition of acetoclastic methanogens by ammonia and $\mathrm{pH}$ in poultry manure digestion. Biol. Wastes 32, 285-297.

[23] KEGG-Database. 2018. Carbon metabolism - Candidatus Methanomassiliicoccus intestinalis Issoire-Mx1, Kyoto Encyclopedia of Genes and Genomes GenomeNet.

[24] Lin, L., Yu, Z., Li, Y., 2017. Sequential batch thermophilic solid-state anaerobic digestion of lignocellulosic biomass via recirculating digestate as inoculum - Part II: Microbial diversity and succession. Bioresour. Technol. 241, 1027-1035.

[25] Liu, Y., Qiao, J.-T., Yuan, X.-Z., Guo, R.-B., Qiu, Y.-L., 2014. Hydrogenispora ethanolica gen. nov., sp. nov., an anaerobic carbohydrate-fermenting bacterium from anaerobic sludge. Int. J. Syst. Evol. Microbiol. 64, 1756-1762.

[26] Lyu, Z., Lu, Y., 2015. Comparative genomics of three Methanocellales strains reveal novel taxonomic and metabolic features. Environ. Microbiol. Rep. 7, 526537. 
[27] Massé, D.I., Rajagopal, R., Singh, G., 2014. Technical and operational feasibility of psychrophilic anaerobic digestion biotechnology for processing ammonia-rich waste. Appl. Energy 120, 49-55.

[28] Menes, R.J., Muxí, L., 2002. Anaerobaculum mobile sp. nov., a novel anaerobic, moderately thermophilic, peptide-fermenting bacterium that uses crotonate as an electron acceptor, and emended description of the genus Anaerobaculum. Int. J. Syst. Evol. Microbiol. 52, 157-164.

[29] Müller, B., Sun, L., Westerholm, M., Schnürer, A., 2016. Bacterial community composition and fhs profiles of low- and high-ammonia biogas digesters reveal novel syntrophic acetate-oxidising bacteria. Biotechnol. Biofuels 9, 48 .

[30] Niu, L., Song, L., Liu, X., Dong, X., 2009. Tepidimicrobium xylanilyticum sp. nov., an anaerobic xylanolytic bacterium, and emended description of the genus Tepidimicrobium. Int. J. Syst. Evol. Microbiol. 59, 2698-2701.

[31] Niu, Q., Qiao, W., Qiang, H., Li, Y.-Y., 2013. Microbial community shifts and biogas conversion computation during steady, inhibited and recovered stages of thermophilic methane fermentation on chicken manure with a wide variation of ammonia. Bioresour. Technol. 146, 223-233.

[32] Nobu, M.K., Narihiro, T., Rinke, C., Kamagata, Y., Tringe, S.G., Woyke, T., Liu, W.-T., 2015. Microbial dark matter ecogenomics reveals complex synergistic networks in a methanogenic bioreactor. ISME J. 9, 1710.

[33] Poirier, S., Madigou, C., Bouchez, T., Chapleur, O., 2017. Improving anaerobic digestion with support media: Mitigation of ammonia inhibition and effect on microbial communities. Bioresour. Technol. 235, 229-239. 
[34] Popp, D., Harms, H., Sträuber, H., 2016. The alkaloid gramine in the anaerobic digestion process - inhibition and adaptation of the methanogenic community. Appl. Microbiol. Biotechnol. 100, 7311-7322.

[35] Ruiz-Sánchez, J., Campanaro, S., Guivernau, M., Fernández, B., Prenafeta-Boldú, F.X., 2018. Effect of ammonia on the active microbiome and metagenome from stable full-scale digesters. Bioresour. Technol. 250, 513-522.

[36] Saeed, A.I., Bhagabati, N.K., Braisted, J.C., Liang, W., Sharov, V., Howe, E.A., Li, J., Thiagarajan, M., White, J.A., Quackenbush, J., 2006. [9] TM4 Microarray Software Suite, Methods in Enzymology. Academic Press, pp. 134-193.

[37] Schnürer, A., Bernhard Schink, and Bo H. Svensson. 1996. Clostridium ultunense sp. nov., a mesophilic bacterium oxidizing acetate in syntrophic association with a hydrogenotrophic methanogenic bacterium. Int. J. Syst. Evol. Microbiol. 46, 1145-1152.

[38] Schnürer, A., Nordberg, A., 2008. Ammonia, a selective agent for methane production by syntrophic acetate oxidation at mesophilic temperature. Water Sci. Technol. 57, 735-740.

[39] Sun, L., Müller, B., Westerholm, M., Schnürer, A., 2014. Syntrophic acetate oxidation in industrial CSTR biogas digesters. J. Biotechnol. 171, 39-44.

[40] Tian, H., Fotidis, I.A., Kissas, K., Angelidaki, I., 2018a. Effect of different ammonia sources on aceticlastic and hydrogenotrophic methanogens. Bioresour. Technol. 250, 390-397.

[41] Tian, H., Fotidis, I.A., Mancini, E., Angelidaki, I., 2017. Different cultivation methods to acclimatise ammonia-tolerant methanogenic consortia. Bioresour. Technol. 232, 1-9. 
[42] Tian, H., Fotidis, I.A., Mancini, E., Treu, L., Mahdy, A., Ballesteros, M., González-Fernández, C., Angelidaki, I., 2018b. Acclimation to extremely high ammonia levels in continuous biomethanation process and the associated microbial community dynamics. Bioresour. Technol. 247, 616-623.

[43] Treu, L., Campanaro, S., Kougias, P.G., Sartori, C., Bassani, I., Angelidaki, I., 2018. Hydrogen-Fueled Microbial Pathways in Biogas Upgrading Systems Revealed by Genome-Centric Metagenomics. Front. Microbiol. 9.

[44] Vajda, B., Bélafi-Bakó, K., Nemestóthy, N., 2011. The role of methanol inmicrobial fuel cells. Hung. J. Ind. Chem. 39, 387-390.

[45] Westerholm, M., Roos, S., Schnürer, A., 2010. Syntrophaceticus schinkii gen. nov., sp. nov., an anaerobic, syntrophic acetate-oxidizing bacterium isolated from a mesophilic anaerobic filter. FEMS Microbiol. Lett. 309, 100-104.

[46] Westerholm, M., Roos, S., Schnürer, A., 2011. Tepidanaerobacter acetatoxydans sp. nov., an anaerobic, syntrophic acetate-oxidizing bacterium isolated from two ammonium-enriched mesophilic methanogenic processes. Syst. Appl. Microbiol. $34,260-266$.

[47] Yenigün, O., Demirel, B., 2013. Ammonia inhibition in anaerobic digestion: A review. Process Biochem. 48, 901-911.

[48] Zhu, X., Treu, L., Kougias, P.G., Campanaro, S., Angelidaki, I., 2017. Characterization of the planktonic microbiome in upflow anaerobic sludge blanket reactors during adaptation of mesophilic methanogenic granules to thermophilic operational conditions. Anaerobe 46, 69-77. 
[49] Zinder, S., Sowers, K., Ferry, J., 1985. Methanosarcina thermophila sp. nov., a thermophilic, acetotrophic, methane-producing bacterium. Int. J. Syst. Evol. Microbiol. 35, 522-523.

[50] Zinder, S.H., Koch, M., 1984. Non-aceticlastic methanogenesis from acetate: acetate oxidation by a thermophilic syntrophic coculture. Arch. Microbiol. 138, 263-272. 


\section{Figure Legends}

Fig. 1. Maximum specific growth rate ( $\mu$ max) of different inocula at different steps of the enrichment process. M1, M2, T1, T2 and T3 stands for Fangel, Hashøj, Blåhøj, Ribe and Snertinge. Error bars come from the triplicates of each setup.

Fig. 2. ${ }^{14} \mathrm{CO}_{2} /{ }^{14} \mathrm{CH}_{4}$ ratio of the ammonia-tolerant consortia based on radioactivity analysis. M1, M2, T1, T2 and T3 stands for Fangel, Hashøj, Blåhøj, Ribe and Snertinge. Error bars derived from the triplicate of each setup.

Fig. 3. Beta diversity of the triplicate samples of the ammonia-tolerant consortia based on principal component analysis. PCo1: principal coordinate 1. PCo2: principal coordinate 2. M1, M2, T1, T2 and T3 stands for Fangel, Hashøj, Blåhøj, Ribe and Snertinge, respectively.

Fig. 4. Taxonomic classification of the archaea at a) order and b) genus levels, and bacteria at c) phylum and d) genus levels of the ammonia-tolerant consortia. Phylum, and genus with relative abundance less than $0.5 \%$ were classified as “Others”. M1, M2, T1, T2 and T3 stands for Fangel, Hashøj, Blåhøj, Ribe and Snertinge. 
Fig. 5. Relative abundance (with respect to the whole community) of interesting OTUs of a) mesophilic and b) thermophilic ammonia-tolerant consortia. M1, M2, T1, T2 and T3 stands for Fangel, Hashøj, Blåhøj, Ribe and Snertinge. 


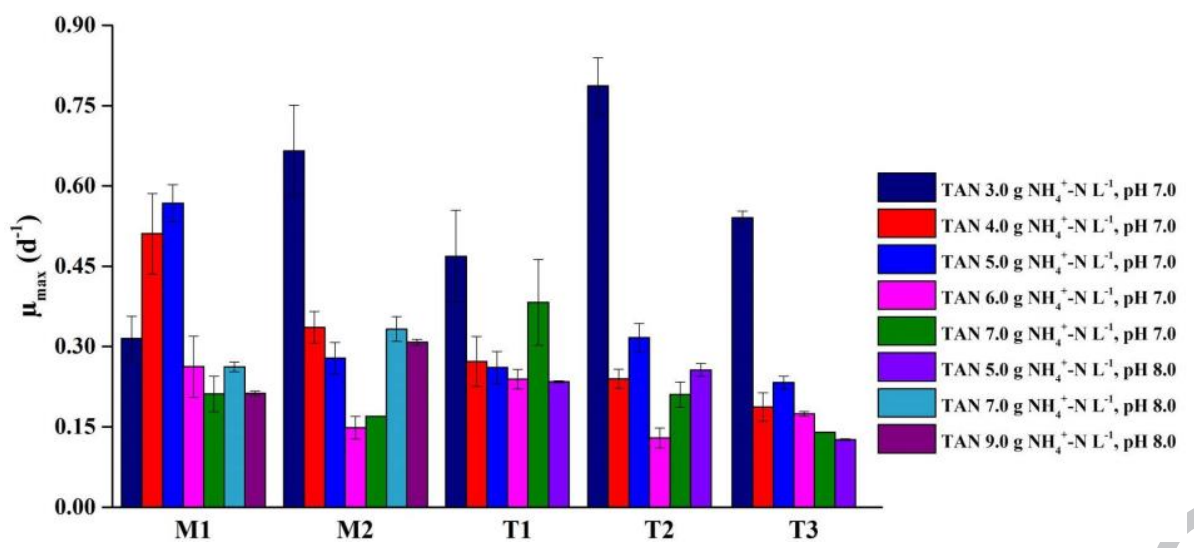




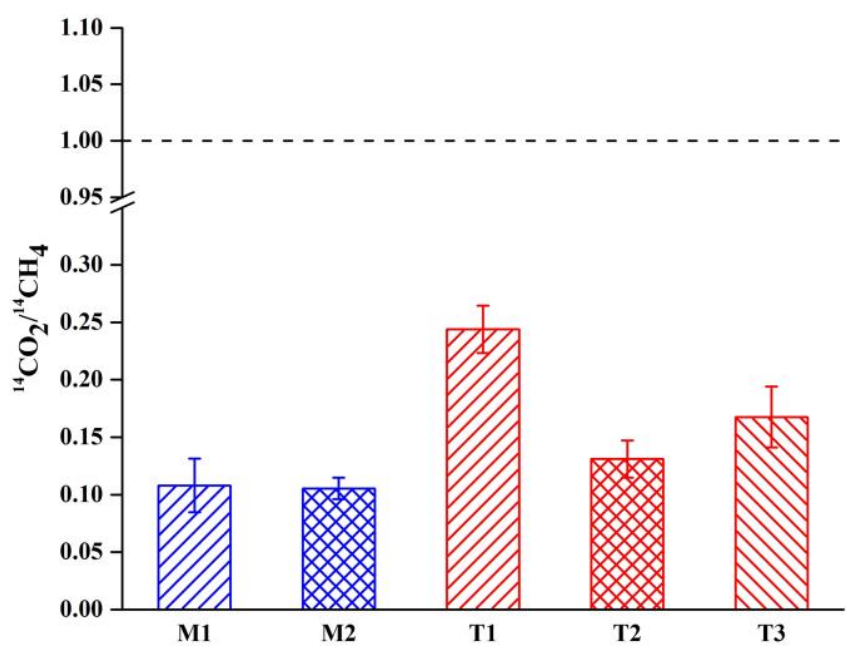




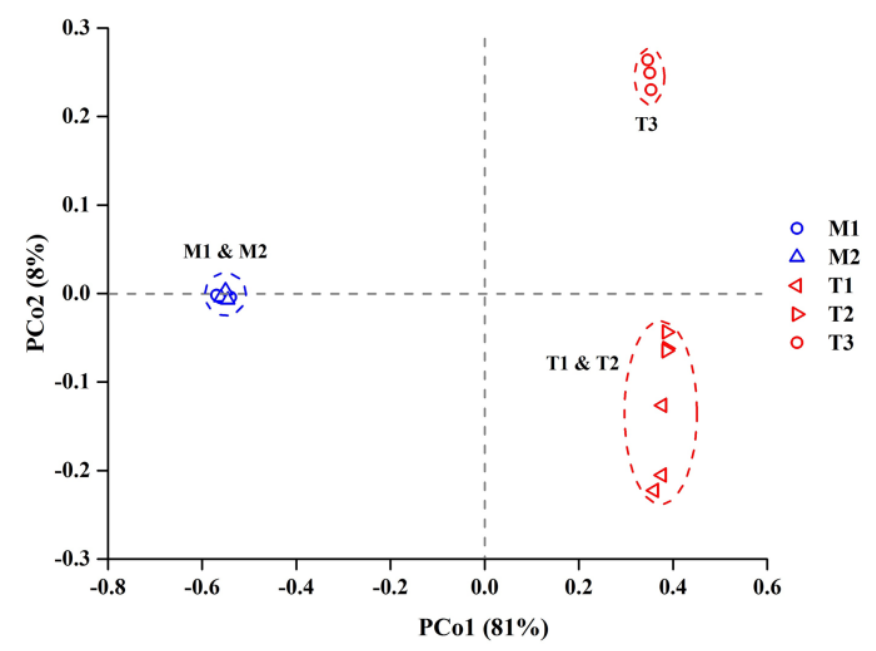


a)
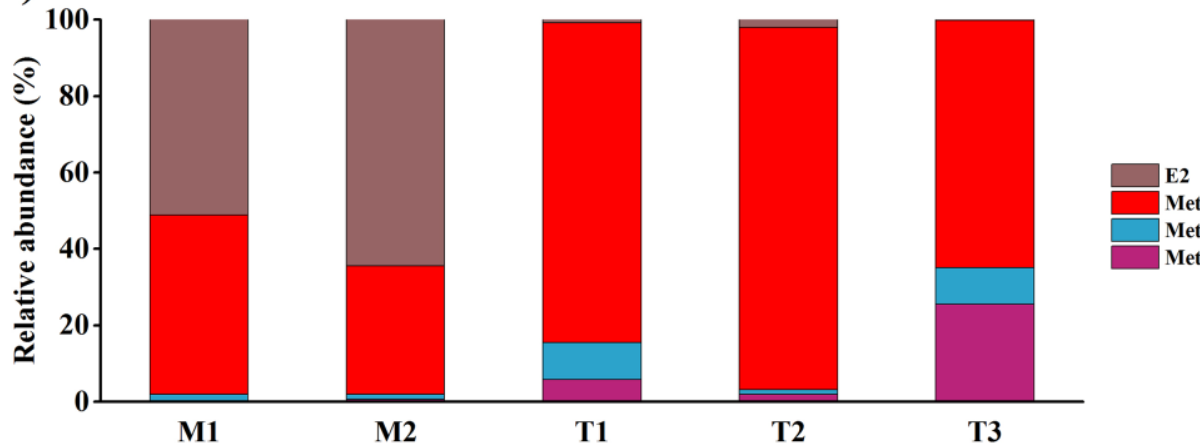

Methanosarcinales

Methanomicrobiales

Methanobacteriales

b)

Archaea- Genus level

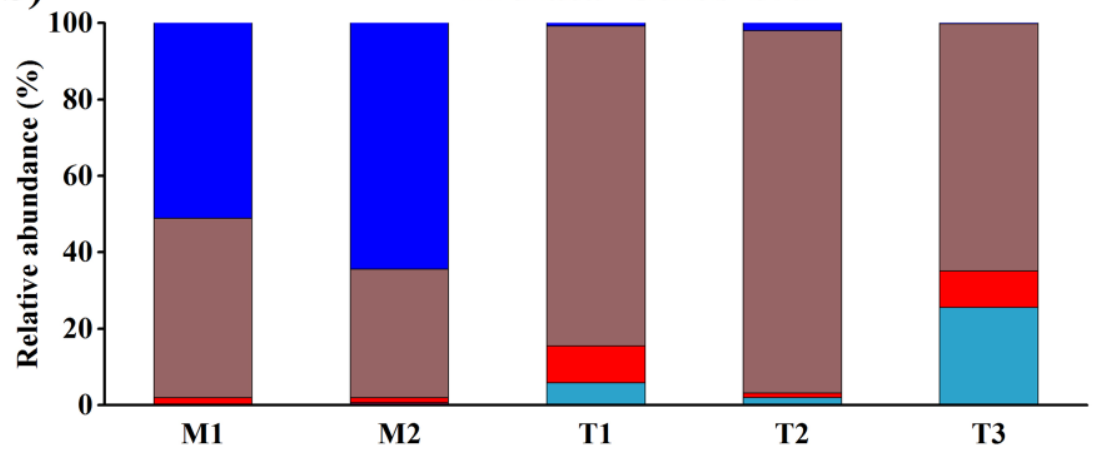

Methanomassiliicoccus

Methanosarcina

Methanoculleus

Methanothermobacter

Methanobacterium

c)

Bacteria- Phylum level
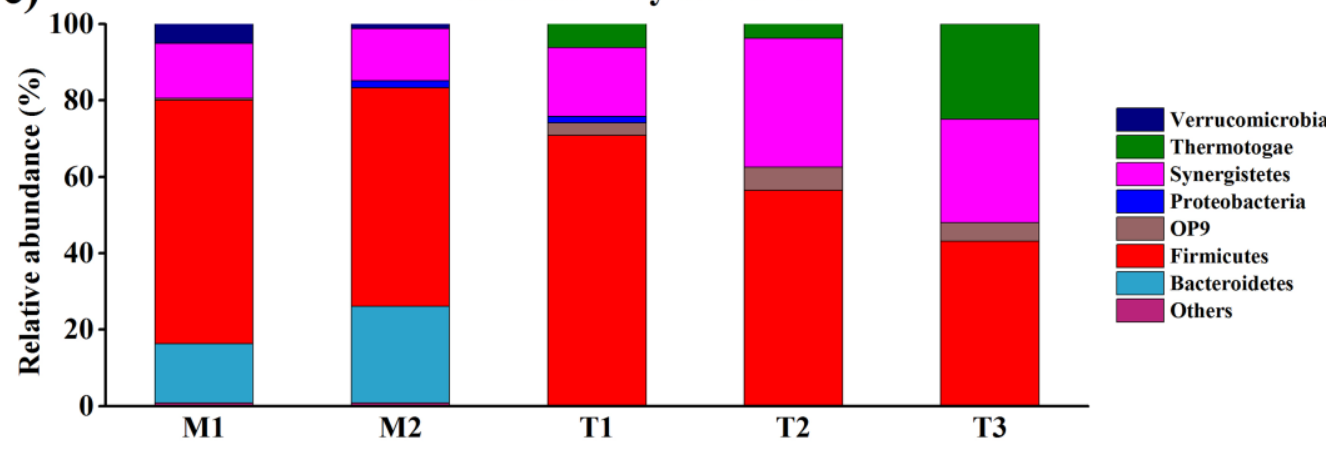

d)

Bacteria- Genus level

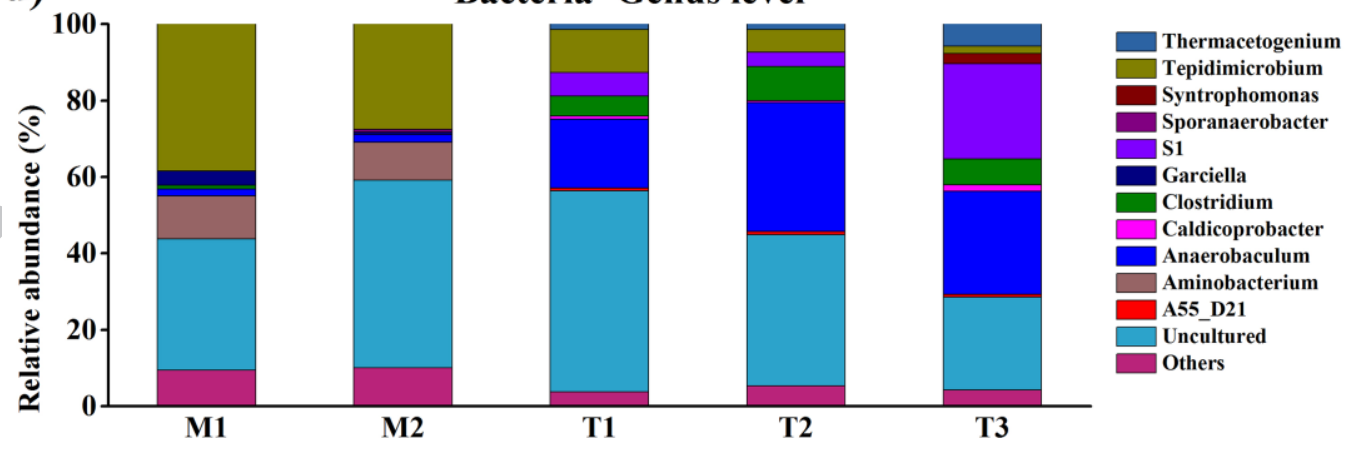


a) 0 M1 M2

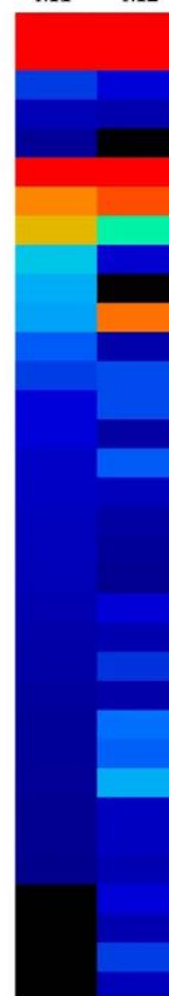

b)

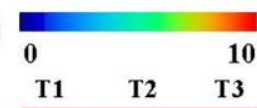

Methanomassiliicoccus luminyensis 1

Methanosarcina soligelidi 2

Methanomassiliicoccus 3

Methanoculleus palmolei 4

Methanosarcina thermophila 5

Tepidimicrobium sp. 6

Fermentimonas caenicola 7

Aminobacterium colombiense 8

R4-41B sp. 9

Clostridia sp. 10

Urmitella timonensis 11

Garciella sp. 12

Anaerobaculum mobile 13

SB-1 sp. 14

Eubacteriaceae sp. 15

SHA-98 sp. 16

Tissierella sp. 17

Clostridiaceae sp. 18

Bacteroidales sp. 19

MBA08 sp. 20

Clostridium ultunense 21

MBA08 sp. 22

Aminiphilaceae sp. 23

Clostridium ultunense 24

GZKB119 sp. 25

Aminobacterium mobile 26

Petrimonas sp. 27

Bacteroidales sp. 28

Tepidimicrobium sp. 29

Clostridiales sp. 30

Sulfurospirillum sp. 31

Tissierella sp. 32

Ruminococcaceae sp. 33

Anaerosalibacter massiliensis 34

T3

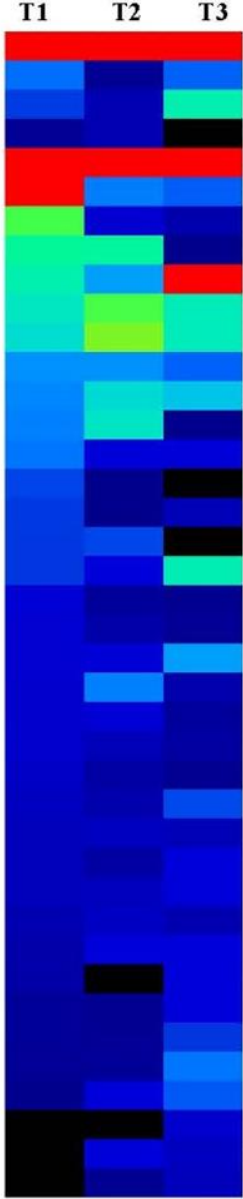

Methanosarcina thermophila 1

Methanoculleus thermophilus 2

Methanothermobacter spp. 3

Methanomassiliicoccus sp. 4

Anaerobaculum mobile 5

Clostridia sp. 6

Tepidimicrobium ferriphilum 7

Peptococcaceae sp. 8

Defluviitoga tunisiensis 9

MBA08 sp. 10

Clostridiaceae sp. 11

D2 sp. 12

OPB72 sp. 13

Tepidimicrobium xylanilyticum 14

BSA2B-08 sp. 15

Pseudomonas sp. 16

MBA08 sp. 17

Tepidimicrobium xylanilyticum 18

Syntrophaceticus schinkii 19

Tissierella sp. 20

Tepidanaerobacter syntrophicus 21

Caldicoprobacter sp. 22

Tepidimicrobium sp. 23

Tepidanaerobacter sp. 24

Haloplasmataceae sp. 25

Tepidimicrobium sp. 26

Caldicoprobacteraceae sp. 27

Anaerobrancaceae sp. 28

Peptococcaceae sp. 29

Clostridiaceae sp. 30

OPB54 sp. 31

Thermoanaerobacterales sp. 32

Tepidanaerobacter syntrophicus 33

Thermoanaerobacter sp. 34

Tepidimicrobium sp. 35

Syntrophomonas bryantii 36

Defluviitoga tunisiensis 37

Caldicoprobacter sp. 38

Peptococcaceae sp. 39

OPB5 4 sp. 40 
Table 1. The characteristics of the used inocula and the operational parameters of the full-scale biogas plants, where the inocula derived from.

\begin{tabular}{|c|c|c|c|c|c|}
\hline & $\begin{array}{l}\text { Fangel } \\
\text { (M1) }\end{array}$ & $\begin{array}{l}\text { Hashøj } \\
\text { (M2) }\end{array}$ & $\begin{array}{l}\text { Blåhøj } \\
\text { (T1) }\end{array}$ & $\begin{array}{l}\text { Ribe } \\
\text { (T2) }\end{array}$ & $\begin{array}{l}\text { Snertinge } \\
\text { (T3) }\end{array}$ \\
\hline Temp. $\left({ }^{\circ} \mathrm{C}\right)$ & $37 \pm 1$ & $37 \pm 1$ & $53 \pm 1$ & $53 \pm 1$ & $53 \pm 1$ \\
\hline HRT (days) & 21 & 20 & 15 & 11 & 20 \\
\hline $\mathrm{pH}$ & 8.10 & 7.92 & 7.88 & .93 & 7.77 \\
\hline $\operatorname{VFA}\left(\mathrm{mg} \mathrm{L}^{-1}\right)$ & $85.35 \pm 3.98$ & $142.76 \pm 15.97$ & $568.61 \pm 32.13$ & $67.78 \pm 9.40$ & $537.49 \pm 27.05$ \\
\hline $\begin{array}{l}\text { TAN } \\
\left(\mathrm{g} \mathrm{NH}_{4}^{+}-\mathrm{N} \mathrm{L} \mathrm{L}^{-}\right.\end{array}$ & $4.68 \pm 0.04$ & $3.99 \pm 0.07$ & $4.12 \pm 0.14$ & $3.11 \pm 0.12$ & $3.67 \pm 0.05$ \\
\hline$\left.{ }^{1}\right)$ & & & & & \\
\hline $\begin{array}{l}\text { FAN } \\
\left(\mathrm{g} \mathrm{NH}_{3}-\mathrm{N} \mathrm{L}^{-1}\right)\end{array}$ & $0.65 \pm 0.01$ & $0.39 \pm 0.01$ & $0.86 \pm 0.02$ & $0.71 \pm 0.03$ & $0.62 \pm 0.01$ \\
\hline $\mathrm{TS}\left(\mathrm{g} \mathrm{L}^{-1}\right)$ & $35.00 \pm 0.70$ & $41.02 \pm 0.28$ & $43.50 \pm 0.12$ & $36.10 \pm 0.14$ & $20.61 \pm 0.01$ \\
\hline $\operatorname{VS}\left(\mathrm{g} \mathrm{L}^{-1}\right)$ & $21.70 \pm 0.23$ & $24.63 \pm 0.22$ & $29.18 \pm 0.11$ & $23.72 \pm 0.15$ & $13.57 \pm 0.06$ \\
\hline
\end{tabular}

* Temp: temperature; HRT: Hydraulic retention time; VFA: Volatile fatty acids; TAN:

Total ammonia; FAN: free ammonia; TS: Total solids; VS: Volatile solids. 
Table 2. Experimental setup of the stepwise enrichment process

\begin{tabular}{lllllll}
\hline \multirow{2}{*}{ Enrichment } & \multicolumn{3}{l}{ Mesophilic inocula } & \multicolumn{3}{l}{ Thermophilic inocula } \\
\cline { 2 - 7 } & TAN & $\mathrm{pH}$ & FAN & TAN & $\mathrm{pH}$ & FAN \\
& $\mathrm{g} \mathrm{NH}_{4}{ }^{+}-\mathrm{N} \mathrm{L}^{-1}$ & & $\mathrm{mg} \mathrm{NH}_{3}-\mathrm{N} \mathrm{L}^{-1}$ & $\mathrm{~g} \mathrm{NH}_{4}^{+}-\mathrm{N} \mathrm{L}^{-1}$ & & $\mathrm{mg} \mathrm{NH}_{3}-\mathrm{NL}^{-1}$ \\
\hline 1 & 3.0 & 7.0 & 38.2 & 3.0 & 7.0 & 112.9 \\
2 & 4.0 & 7.0 & 50.9 & 4.0 & 7.0 & 150.5 \\
3 & 5.0 & 7.0 & 63.7 & 5.0 & 7.0 & 188.1 \\
4 & 6.0 & 7.0 & 76.4 & 6.0 & 7.0 & 225.8 \\
5 & 7.0 & 7.0 & 89.1 & 7.0 & 7.0 & 263.4 \\
6 & 7.0 & 8.0 & 799.8 & 5.0 & 8.0 & 1405.5 \\
7 & 9.0 & 8.0 & 1028.3 & - & - & - \\
\hline
\end{tabular}




\section{Highlights}

- Acclimatization of methanogenic consortia to extreme ammonia levels

- Methanomassiliicoccus luminyensis consumes acetate to produce biomass but not $\mathrm{CH}_{4}$

- Strict methylotrophic M. luminyensis was dominant at $37^{\circ} \mathrm{C}$ in acetate-fed reactors

- Aceticlastic pathway was dominant at extreme ammonia levels

- Methanosarcina spp. (M. thermophila \& M. soligelidi) were vital at high FAN levels 


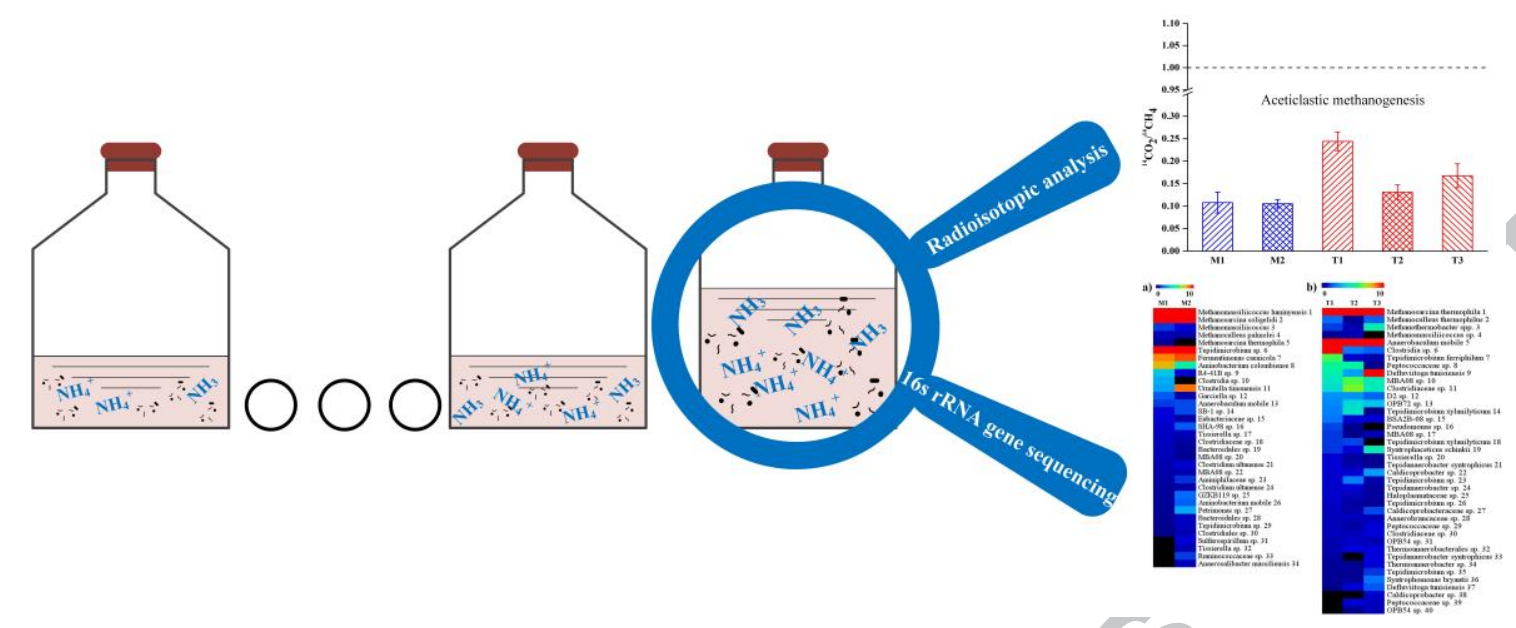

